\title{
ESTUDO DA LACTAÇÃO EM MULHERES DO DISTRITO DE SÃO PAULO, BRASIL
}

João Yunes*

Vera Shirley C. Ronchezel **

RSPU-B/259

YUNes, J. \& Ronchezel, V.S. - Estudo da lactução em mulheres do Distrito de São Paulo. Brasil. Rev. Saúde públ., S. Paulo, 9:191-213, 1975.

- Resimo: Foi feito um estudo sobre as inter-relucões existentes entre " lactucão, fertiludade e variáveis sócio-economicas em uma umostra de mulheres do Distrito de São Paulo, Brasil. Constatou-se que o tempo de amamentação rura com a paridade, com a idade e a instrução da mulher e com o gasto mensal da família: e também existir relação entre o tempo de amamentação e o mtertalo entre duas gestacoes subsequentes para as mulheres gue näo usam métodos anticoncejcionais.

Unitermos: Amamentação. Lactação. Paridade.

\section{IXTRODLCAO}

Este trabalho baseia-se nos dadus da pesquisa realizada en mulheres do Distrito de São Paulo **.. Antes de se analisar os resultados, serão apresentadas as principais conclusões de estudos semelhantes realizados em outros paises. Esta revisão da literatura se prende aos principais fatores demográficos sociais. econômicos e hiológicos que apresentam alguma associação ou relação com o hálito e a duração da amamentação. hem como seu ('teito na fisiologia da reprodução humana medida através da concepção.

(): dados referentes à duração do tempo de amamenlação variam nas diversas regióes do mundo na medida em que as situaçōes econômicas e padrões culturais também são diferentes. As mães indus amamentavam seus filhos. em média. durante 21 meses (Potter"). as inglesas 5.5 meses (Cuttmacher'. 1952, e as chinesas de Formosa. 16 meses (Jain e col. 1972). Os dados mais recentes mostram que. nos países desenvolvidos. as mães lactantes não excedem a $20 \%$ e o periodo de lactação é breve. Por outro lado. em muitos dos países em desenvolvimento. cerca de $90 \%$ \% das mães amamentam seus filhos durante um período que varia de 2 a 36 meses.

Em relação à paridade ohservou-se que as mães primíparas tendem a amamentar

* Do Centro de Estudos de Dinâmica Populacional (CEDIP) da Faculdade de Saúde Pública da USP - Av. Dr. Arnaldo, 715 - São Paulo, SP - Brasil; Da Disciplina de Pediatria Social à Friculdade de Medicina da USP; Da Divisão de Epidemiologia do Departamento 'récnico Normativo da Secretaria de Estado da Saúde

* Da Divisão de Epidemiologia do Departamento Técnico Normativo da Secretaria do Estado da Saúde - Rua Teodoro Sampaio, 833 - São Paulo, SP - Brasil

** Pesquisa realizada em 1965, pela Prof.a E. Berquó e os membros do entāo Departamentr, de Estatistica Aplicada à Saúde Pública da Faculdade de Saúde Púnula da lisP 
YUNES, J. \& RONCHEZEL, V.S. - Estudo da lactação em mulheres do Distrito de São Paulo, Brasil. Rev. Saúde pübl., S. Paulo, 9:191-213, 1975.

mais os recém-nascidos do que as multíparas, embora estatisticamente a diferença não tenha sido significativa nos estudos de Robertson ${ }^{10}$. Segundo este autor, o desmame é mais precoce nas multíparas, e a idade materna não tem influência na mudança da quantidade ou composição do leite materno. Neste mesmo 'studo, constatou-se que as mães com nível educacional até o primeiro ciclo ou nível universitário tendem a amamentar seus filhos mais do que as que têm o segundo ciclo. A amamentação foi também mais comum nas mulheres de classe social baixa e alta que nas de classe média. Segundo Jain e col. ", em seu estudo em Formosa, a duração média da lactação das mães aumenta com a paridade (ao ('ontrário de Rohertson ${ }^{10}$ ) e com a idade materna, sendo de 13 meses para mulheres com menos de 25 anos de idade e de 20 meses para mulheres com mais de 40 anos. A duração média da lactação, neste estudo, variou de 11 meses para a paridade 1 , até 18 meses para as mulheres com mais de 8 filhos. Da mesma maneira, o período de amenorréia aumentou com o aumento da idade e paridade e para cada uma destas o período de amenorréia é substancialmente maior para as mães que amamentam do que para aquelas que não amamentam. Enquanto a idade e paridade estão associadas com a duração da amamentação e amenorréia, aquela é muito mais importante do que esta durante o período de lactação.

Durante este período, há uma fase de amenorréia e anovulação cuja duração varia consideravelmente. É desconhecido o mecanismo exato desta inibição ovárica.

Taylor apud Chopra ${ }^{3}$ diz que a amenorréia pós-parto dura de 6 a 8 semanas na ausência da lactação e que nas populações que praticam a amamentação natural, o período de infecundidade deveria ser equivalente a $3 / 4$ do período médio da lactação.
Tietze $^{12}$ afirma que, na ausência de lactação, a duração média de amenorréia depois do parto é de 6 a 8 semanas. Se é certo que a lactação pode ser acompanhada de amenorréia prolongada e supressão da ovulação, convém recordar que há um risco de $5 \%$ de conceber durante a amenorréia pós-parto, risco este que aumenta rapidamente logo que reaparece a menstruação.

Lyon \& Stamn ${ }^{6}$ encontraram ciclos anovulatórios em 95\% dos casos estudados durante a primeira menstruação pósparto. Udesky ${ }^{1.3}$ encontrou em todos os seus casos ciclos anovulatórios durante o período da primeira menstrução e $50 \%$ na segundo. $O$ terceiro ciclo menstrual foi $100 \%$ ovulatório. Peckham ${ }^{8}$ em seus estudos refere que $1 / 10$ das mulheres engravidam sem terem tido nenhuma menstruação.

Mc Keown ' reportou em seu estudo que $7 \%$ das mulheres de sua amostra conceberam dentro de um ano após o parto. Guttmacher ${ }^{4}$ reportou os achados de Douglas, concluindo que em mães lactantes a chance de conceber durante os primeiros nove meses após o parto foi menor do que as das mães não lactantes, e de nove a dez meses após o parto ambos os grupos tiveram igual probabilidade de fecundar.

Taylor apud Chopra ${ }^{3}$ assinala que, aproximadamente, metade das mulheres concebeu nos três meses do período menstrual posterior ao parto e $80 \%$ ao fim de um ano.

Outro problema que se levanta em relação ao período de esterilidade durante a amenorréia pós-parto é se isto poderia ser devido à baixa freqüência das relações sexuais ou mesmo tabus sociais com relação ao coito. Potter e col. ${ }^{9}$ em estudo realizado na Índia observaram que cerca de $2 / 3$ das mulheres reportaram abstinência de coito por menos de 4 meses, $20 \%$ por 5 a 6 e $15 \%$ por 7 . 
YUNES, J. \& RONCHEZEL, V.S. - Estudo da lactação em mulheres do Distrito de São Paulo, Brasil. Rev. Saúde públ., S. Paulo, 9:191-213, 1975.

O objetivo de nosso estudo foi verificar:

1. ${ }^{\circ}$ Variação do tempo médio de amamentação em relação à paridade ou ordem de nascimentos (de 1 a 5 ) e idade da mulher.

$2 .^{\circ}$ ) Tempo de amamentação das mulheres que usaram ou não contraceptivos segundo a paridade e idade da mulher.

$\left.3 .^{\circ}\right)$ Inter-relação entre amamentação. e fertilidade.

4. $\left.{ }^{\circ}\right)$ Tempo médio de amamentação segundo a situação sócio-econômica (grau de instrução e gasto mensal da família) e. origem da mulher.

\section{METODOLOGIA}

Os dados elaborados e interpretados, conforme foi mencionado, foram extraídos do levantamento retrospectivo de Pesquisa sobre Reprodução Humana no Distrito de São Paulo. A população em estudo foi constituída pelas mulheres não solteiras de 15 a 49 anos completos e residentes no Distrito de São Paulo, em 1965. A amostra escolhida constou de 2.857 mulheres, ou seja, $0,25 \%$ do total da população, das quais 2.647 tiveram pelo menos um nascido vivo até a época da enl:evista (Berquó e col. ${ }^{1}$ + Camargo e Berquó $\left.{ }^{2}\right)$.

A variável "tempo de amamentação" foi dẹfinida como a duração da amamentação do recém-nascido vivo. Para efeito de análise as mulheres foram divididas em 9 subgrupos que se seguem:

1 - não amamentou

2 - amamentou até 3 semanas

3 - amamentou de $3 \mid-6$ semanas

4 - amamentou de 6 semanas -3 meses

5 - amamentou de 3 meses -6 meses

6 - amamentou de 6 meses -9 meses

7 -amamentou de 9 meses -1 ano

8 - amamentou de 1 ano $\mid-2$ anos

9 - amamentou 2 anos e mais.
Os subgrupos 1 e 2 "não amamentou" e "amamentou até 3 semanas" representam as mulheres que não querem ou não podem amamentar seus filhos, ou por algum motivo desistiram da amamentação antes de completar 3 semanas. Os óbitos de crianças ocorridos no período perinatal (menos de 7 dias) ou neonatal (menos de 28 dias), podem refletir no comportamento das mulheres do subgrupo 2.

O subgrupo 3, "3 a 6 semanas" representa o período em que a mulher é em geral aconselhada à abstinência ou diminuição das relações sexuais (40 dias) e, em muitos casos, neste período é que recomeçam as medidas de uso de anti-concepcionais.

Os subgrupos $4,5,6$ e $7, " 6$ semanas a 3 meses"; "3 meses a 6 meses"; "6 meses a 9 meses" e "9 meses a um ano" dividem o ano em quartos (exceto para o subgrupo 9 em que o período é de 4 meses).

O subgrupo 9, "um a 2 anos", foi incluído para possibilitar a comparação com países em que o hábito de amamentação estende-se por períodos longos. Além disso, teve por objetivo separar o período de lactação considerado "normal" das mulheres que amamentam pọr "mais de 2 anos".

As Tahelas a serem analisadas foram elaboradas partindo-se do total de nascidos vivos amamentados. O tempo de amamentação foi dividido em classes: menos de 3 semanas, mais de 3 semanas, mais de $3,6,9$ e 13 meses e mais de 2 anos, $\mathrm{e}$ os nascidos vivos foram distribuídos em números absolutos e em percentagem acumulados.

A classe de menos de 3 semanas para tempo de amamentação foi considerada por apresentar, na maioria das vezes, tendência totalmente inversa das demais.

O tempo médio de amamentação (TMA) foi calculado pela relação que se segue: 
YUNES, J. \& RONCHEZEL, V.S. - Estudo da lactação em mulheres do Distrito de São Paulo. Brasil. Rev. Saúde pübl., S. Paulo, 9:191-213, 1975.

$$
T M A=\frac{X f}{\Sigma f}
$$

em que $\mathrm{X}$ é o ponto médio dos intervalos das classes "duração de amamentação do recém-nascido" considerados e onde f é a distribuição dos recém-nascidos nas respectivas classes. A classe "não amamentou" foi excluída da análise por estarmos querendo obter "tempo médio de amamentação". O ponto médio, da classe "amamentou alé 3 semanas" foi considerado 1,5 semanas. O ponto médio da clas*e "2 anos e mais" foi considerado 110 semanas, ou seja, 27,5 meses. A classe' foi montada considerando-se seu extremo superior igual a 30 meses. O número de semanas em cada mês foi considerado igual a 4 .

Utilizou-se como método estatístico a regressão linear ajustada.

\section{RESUITADOS}

\subsection{Tempo de Amamentação $e$ paridade}

Ao se analisar a amamentação segundo a paridade de 1 a 5 , constata-se, conforme Tabela 1, que a proporção de mulheres que amamentaram seus filhos variou de $86,59 \%$ para o $4 . "$ nascimento vivo. a $88,99 \%$ para o 2.". Portanto, a maio.ia das mulheres amamentou seus filhos.

TABFI. A 1

Relacão entre amamentacão e paridade de mulheres do Distrito de São Paudo

\begin{tabular}{|c|c|c|c|c|c|c|c|c|c|c|}
\hline \multirow{3}{*}{$\begin{array}{c}\text { Ama- } \\
\text { menta- } \\
\text { cão }\end{array}$} & \multicolumn{10}{|c|}{ Pa $\mathrm{r}$ id a d e } \\
\hline & \multicolumn{2}{|c|}{1} & \multicolumn{2}{|c|}{2} & \multicolumn{2}{|c|}{3} & \multicolumn{2}{|c|}{4} & \multicolumn{2}{|c|}{5} \\
\hline & n. ${ }^{\circ}$ & $\%$ & n. ${ }^{\circ}$ & $\%$ & n. ${ }^{\circ}$ & $\%$ & n.o & $\%$ & n. ${ }^{\circ}$ & $\%$ \\
\hline Não & 299 & 11,35 & 231 & 11,01 & 153 & 12,29 & 88 & 13,41 & 48 & 13,00 \\
\hline Sim & 2.336 & 88,65 & 1.867 & 88,99 & 1.092 & 87,71 & 568 & 86,59 & 321 & 87,00 \\
\hline Total & 2.635 & 100,00 & 2.098 & 100,00 & 1.245 & 100,00 & 656 & 100,00 & 369 & 100,00 \\
\hline
\end{tabular}

Em relação ao tempo de amamentação verifica-se que a moda pára cada nascimento vivo foi de $3-5$ meses até a paridade 4 , e de 9-12 meses na paridade 5 (Tabela 2 ). Como de uma maneira geral nas paridades maiores foram de mulheres nos extremos dos estratos sociais, sugere-se como hipótese que o maior tempo de amamentação nessa paridade se deva a fatores predominantemente econômicos no estrato social haixo, e a valorização dos benefícios da amamentação riatural, no estrato mais alto. Embora a tendência seja discreta. nota-se que o háhito de não amamenlar aumenta com a paridade. Considerandose as mulheres que amamentam, nota-se que a duração do tempo médio de lactação aumeta à medida em que o número de filhos cresce. Tal fato pode estar relacionado ao nível sócjo-econômico da família que, provavelmente, tende a diminuir com o aumento da paridade. A duração, por paridade, variou de 30.2 semanas para a paridade 1 e 34,8 para a 5. Portanto, a variedade da duração média do tempo de lactação apresenta aumento discreto em relação a ordem do nascimento, sendo sta amplitude em torno de 4.6 semanas. 
YUNES, J. \& RONCHEZEL, V.S. - Estudo da lactação em mulheres do Distrito de São Paulo, Brasil. Rev. Saúlle públ., S. Paulo, 9:191-213, 1975.

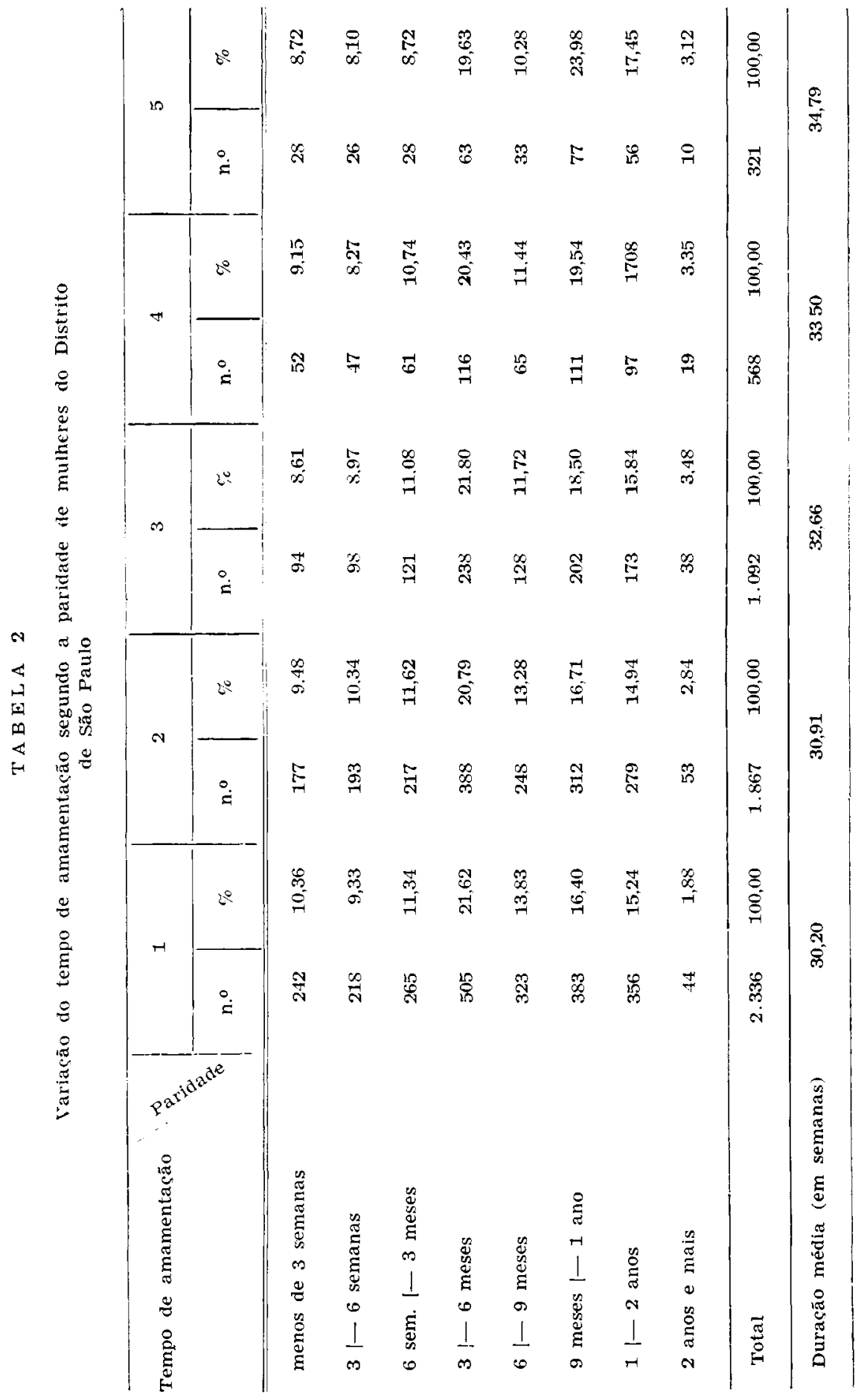


YUNES, J. \& RONCHEZEL, V.S. - Estudo da lactação em mulheres do Distrito de São Paulo, Brasil. Rev. Saúde públ., S. Paulo, 9:191-213, 1975.

Pela observação da regressão ajustada (em que se admitiu que a variável independente, paridade na ocasião, está no $3 .^{\circ}$ nível de mensuração e que se tomou apenas como amplitude de interesse as paridades de 1 a 5 , restringindo-se a paridade 0 ) e dos valores observados parecenos lícito inferir que à medida que a paridade aumenta há um aumento do tempo de amamentação de forma linear, pelo menos para as paridades observadas.

\subsection{Tempo Médio de Amamentação por Paridade Segundo a Idade da. Mulher na Entrevista}

Considerando-se cada coorte de mulheres pode-se observar pela Tabela 3 que diferem as tendências de tempo de amamentação por paridade. Para as mulheres mais jovens (de 15 a 24 anos) observa-se uma diminuição do tempo médio de amamentação à medida que aumenta a paridade. Contudo, pode-se objetar que provavelmente são poucas as mulheres com essas idades que tiveram 5 nascidos vivos ou até mesmo 4. Nota-se, no entanto, que o número total de nascidos vivos deste grupo de mulheres é consideravelmente menor que o dos demais grupos etários, diminuindo de mais de $50 \%$ quando se passa da paridade 2 para a 3 , e sendo de apenas 5 nascidos vivos na paridade 5. Para as mulheres mais velhas (com mais de 35 anos) em que se verifica terem tido mais de $50 \%$ do total dos nascidos vivos, a tendência não difere da tendência geral, ou seja, o tempo mérlio de amamentação aumenta com a paridade.

Ainda pela Tabela 3 , é interessante olservar que o tempo de amamentação, independente da paridade, aumenta, em média, conforme o aumento da idade da muIher. Considerando-se, pois, o total de nascidos vivos de cada coorte, o tempo médio de amamentação das mulheres com mais de 35 anos ( 36,8 semanas) é maior que o das mulheres de 15 a 24 anos $(21,2$ semanas). Tendência semelhante pode ser observada considerando-se as paridades 1 , 2 e 3 , isto é, quanto maior a idade da mulher, maior o tempo médio de amamentação. Com relação às paridades 4 e 5 essas tendências não são tão nítidas, podendo estar influindo neste caso o pequeno número de eventos ocorridos.

\subsection{Tempo de Amamentação Segundo Idade da Mulher na Entrevista}

Através da Tabela 4 em que se esiuda o comportamento das mães em relação ao tempo de amamentação segundo a idade e independente da paridade, observase que apenas $0,83 \%$ dos nascidos vivo: de mães que pertencem à coorte de 15 a 24 anos são amamentados mais de 2 anos, enquanto que $3,57 \%$ dos filhos daquelas da coorte de 35 e mais anos são amamentados por esse mesmo período. Isto levanos a concluir que as mulheres pertencentes a coortes mais novas amamentam menos tempo que as das mais velhas. Observa-se, também, que o aumento de número dos nascidos vivos amamentados por mais de 2 anos se faz gradualmente e de acordo com o aumento de idade das mães. Para os nascidos vivos amamentados menos de 3 semanas observa-se uma tendência inversa, isto é, maior percentagem deles se concentra na coorte mais nova $(16,25 \%)$ e a menor na coorte mais velha $(6,89 \%)$.

Ao se analisar por paridade, ou seja, pela ordem de nascimentos observa-se a mesma tendência, ou seja, as mulheres das coortes mais novas amamentam menos tempo que as mais velhas. A tendencia observada para as demais paridades não aparecem claramente para o $5 .^{\circ}$ nascido vivo. Isso deve-se, possivelmente, ao pequeno número de rasos estudados.

Pela Fig. $1 \mathrm{em}$ que se analisa a distribuição percentual dos nascidos vivos amamentados mais de um ano, observa-se claramente a tendência das mulheres das coortes mais velhas amamentarem mais tempo que as mais novas. 
YUNES, J. \& RONCHEZEL, V.S. - Estudo da lactạão em mulheres do Distrito de São Paulo, Brasil. Rev. saúde públ., S. Paulo, 9:191-213, 1975.

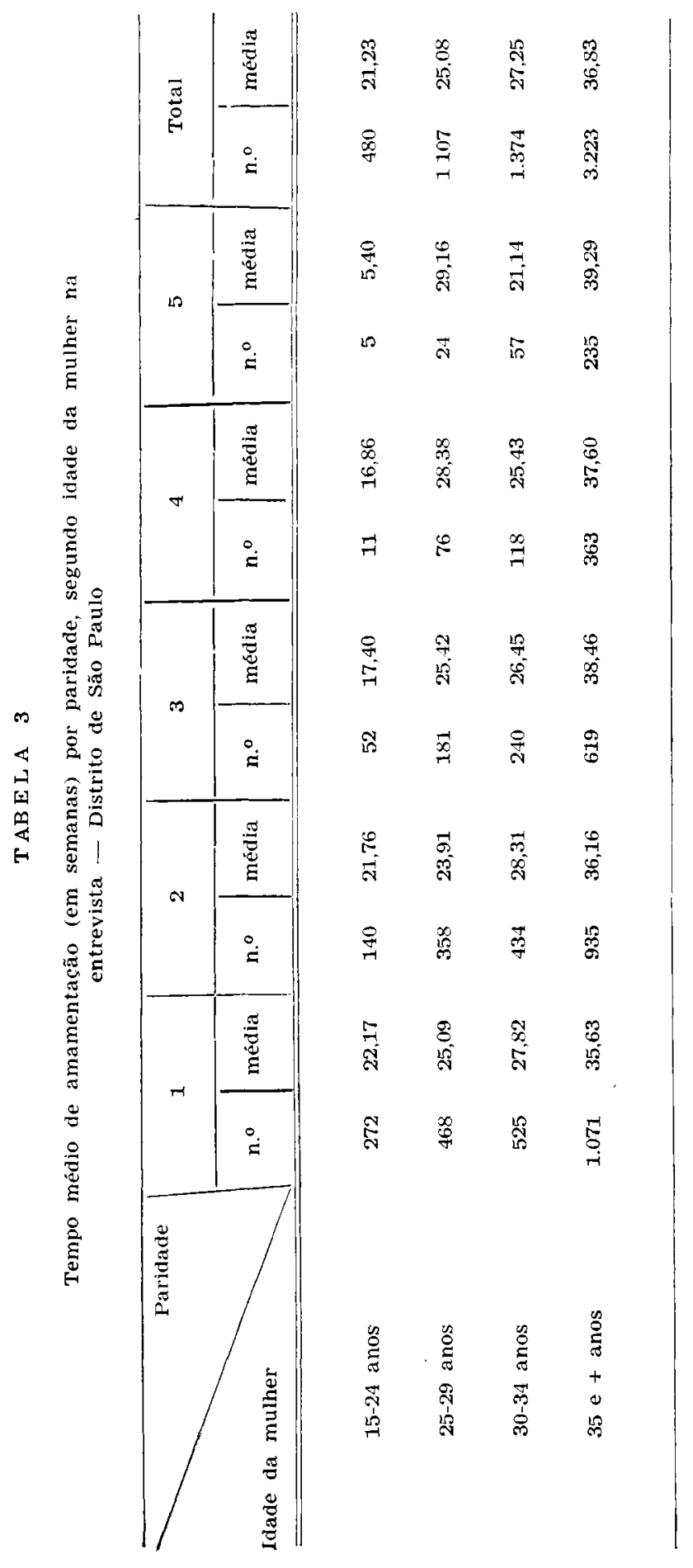


YUNES, J. \& RONCHEZEL, V.S. - Estudo da lactacão em mulheres do Distrito de São Paulo. Brasil. Rev. Saúde pübl., S. Paulo, 9:191-213, 1975.

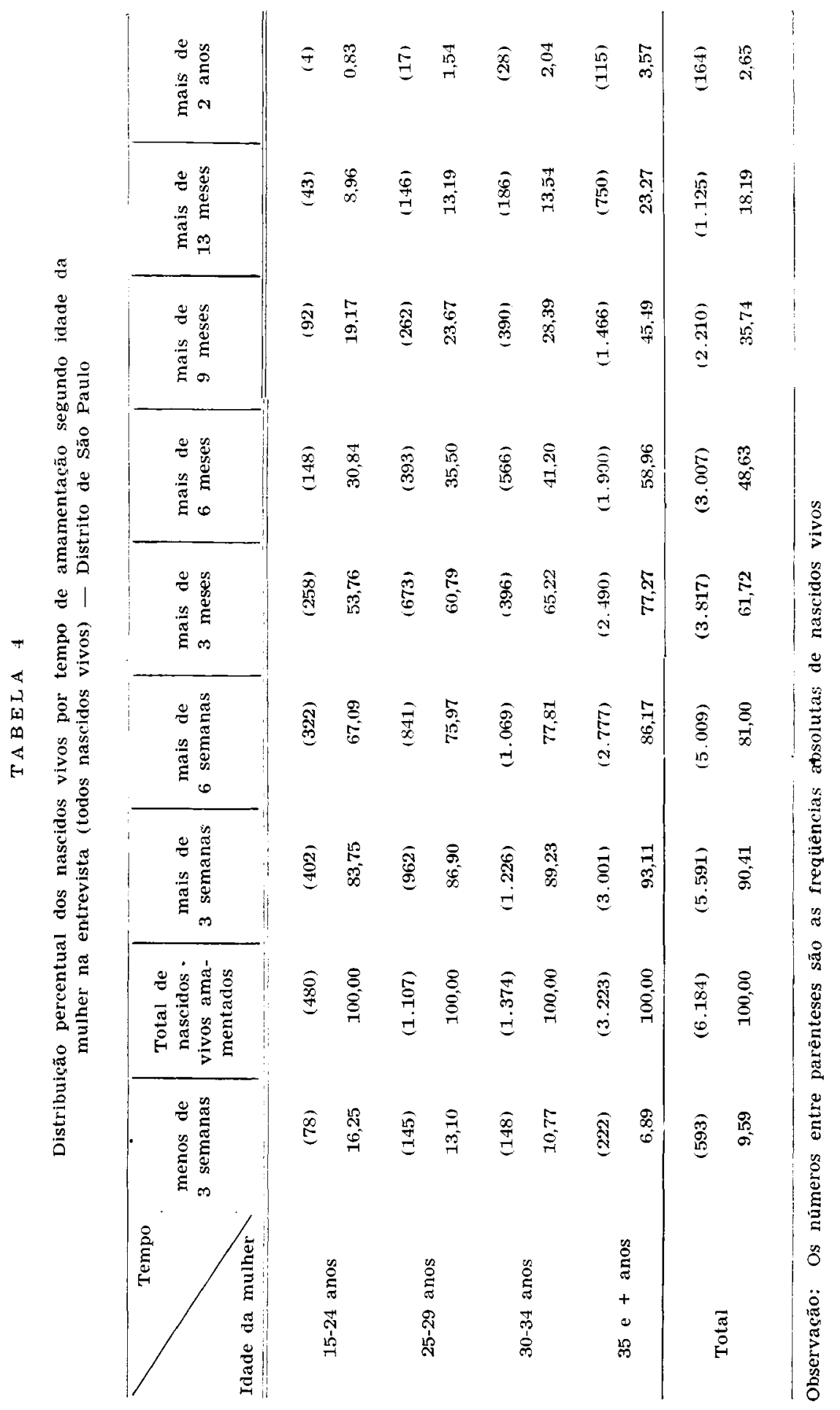


YUNES, J. \& RONCHEZEL̃, V.S. -- Estudo da lactacaão em mulheres do Distrito de Sáo Paulo, Brasil. Rev. Saúule públ., S Paulo, 9:191-213, 1975.

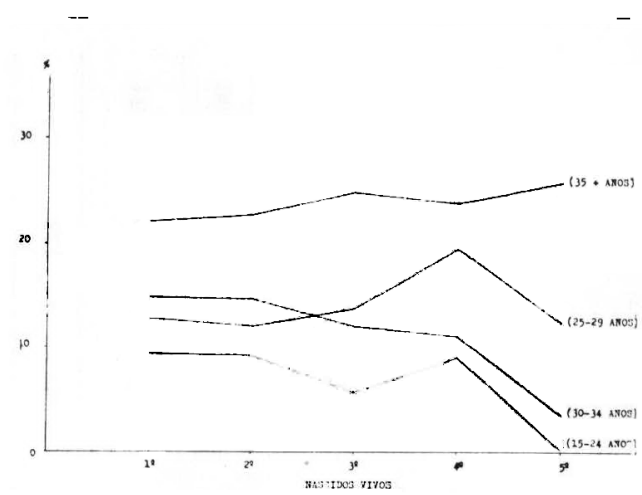

Fig. 1 - Distribuicāo percentual dos našildos vivos amamentados, mais de um ano segundo ordem de nascimento e idade da mulher.

As mulheres mais velhas da amostra rvidenciam, assim, hábito de amamentar seus filhos por um tempo maior que as mais novas. A que fatores se pode atrihuir este hábito é indagável cuja resposta mereceria um estudo esperífico.

\subsection{Tempo d. Amamentação e U/so de Contraceptizos}

A Tabela 5 mostra a distribuição percentual das milheres que utilizaram métodos anticoncepcionais (MAC) logo após o nascimento da criança e aquelas que não usaram, de acordo rom o tempo de amamentação. Nota-se que o número de mulheres que usaram e que não usaram contraceptivos por ordem de nascimento são bastante próximos, com exceção para a paridade 2. A proporção de mulheres que usaram contraceptivos segundo a ordem de nascimento vivo foi sempre maior. com exceção da paridade 5. A proporção daquelas que amamentaram e que não usaram contraceptivos por ordem de nascimento vivo foi de: $46.5 \%$ (paridade 1 ); $37.0 \%$ (paridade 2 ); $41.3 \%$ (paridade $3) ; 48.3 \%$ (paridade 4 ) e $55.4 \%$ (paridade 5 ).

A duração média da amamentação foi calculada usando os suhgrupos 2 a 9, "menos de 3 semanas" até "2 anos e mais".
As mulheres que não amamentaram foram eliminadas para efeito de comparação com outros estudos. A duraçāo midia da amamentação para cada nc cido vivo segundo o uso ou não de métodos anticoncepcionais (MAC) é apresentada na Tabela 5. Notese que há dierença entre os dois grupos. Mães que não usaram contraceplivos mostraram uma tendência a aumentar o tempo de lactação com o aumento de paridade. A partir da rategoria de tempo de lactação de "9 mcses a 1 ano" ohserva-se que as proporçōes destas catcgorias aumentam à modida em que aumenta a paridade. Para as mulheres que usaram contraceptivos não se observa uma tendência nítida. ocorrendo flu uações. Observando-se o tempo médio de amamentação, segundo o uso ou não de métodos anticoncepcionais e segundo a paridade. nota-se ser sempre maior a duraçāo média da amamentação para as mulheres que nāo usaram contraceptivos. Isto sugere a hipótese de que o alongamento da amamentação funciona como meio de prevenir uma nova concepção. Esta hipótese é coerente com a motivação às vezes expressa no contacto clínico, prolongando as mulheres o tempo de lactação como "proteção" contra a concepção. A diferença do tempo médio de lactação entre as que usaram MAC e as que não usaram variou de 3 semanas (paridade 1) a 7.5 (paridade 4), sendo as demais: 7 semanas (paridade 2), 4,5 semanas (paridade 3 ) e 4,7 semanas (paridade 5 ).

Ainda pela Tabela 5, observamos que o tempo de lactação mais freqüente também varia para os dois grupos. Para as mães que usaram contraceptivos a moda do tempo de lactação para cada paridade é de 3 a 5 meses, enquanto que, para as māes que não usaram medidas anticoncepcionais é de 9 meses a 1 ano, exceção para a paridade 1 (moda 3 a 5 meses). As diferenças acima apresentadas podem ser atribuídas em parte a diferenças culturais com padróes de comportamento distintos e à situação sócio-econômica diversa. A hipótese é de que as mães que usam 


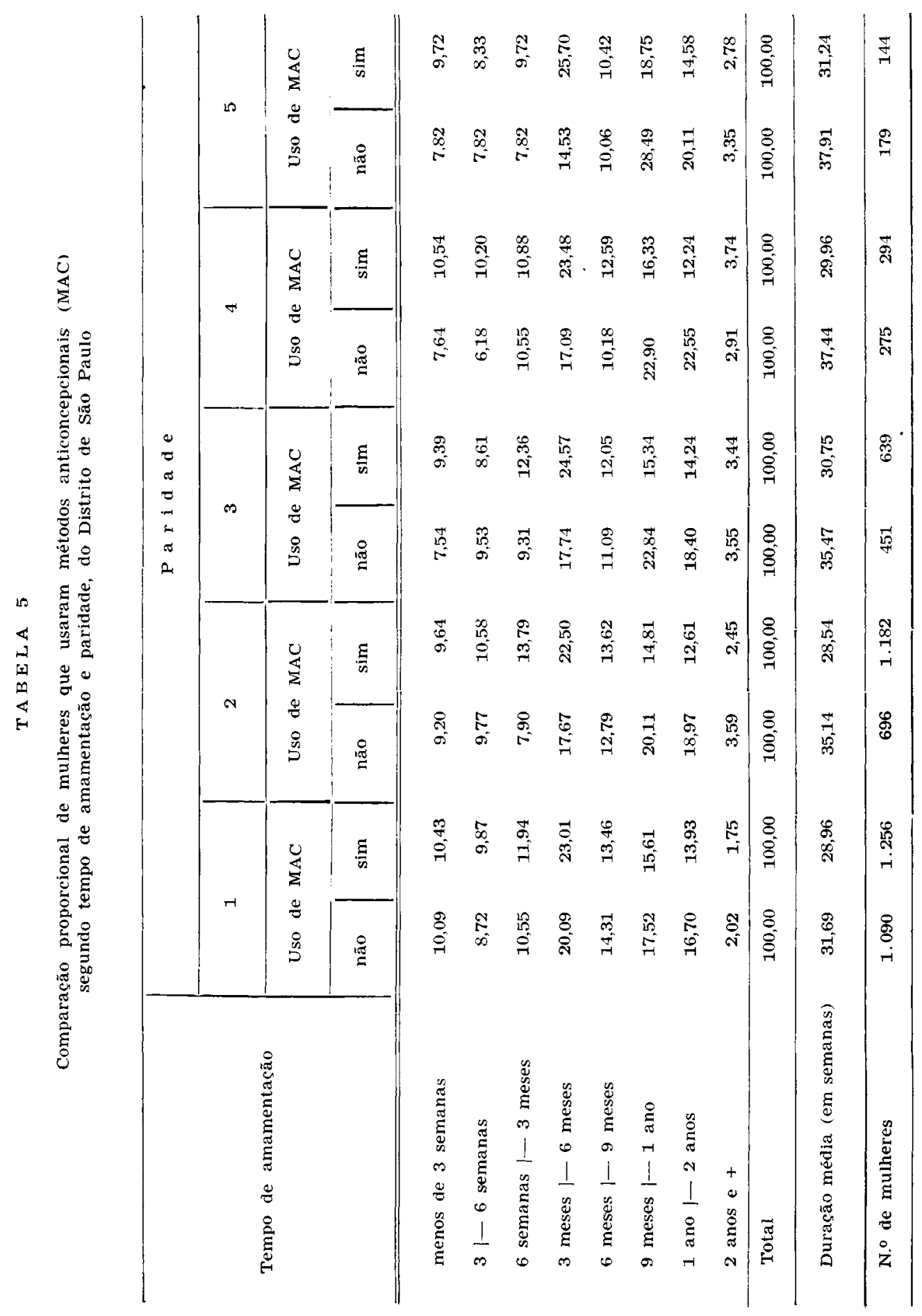


IUNES, J. \& RONCHEZEL, V.S. - Estudo da lactacāo em mulheres do Distrıto de São Paujo, Brasil. Rev. Saúde pribl., S. Paulo, 9:191-213, 1975.

rontraceptivos têm em geral melhor situação sócio-econômica e hábito de amamentar menos freqüente. A implicação nesta diferença parece também estar no fato de que as mulheres que não usam medidas anticoncepcionais amamentam por tempo maior para cada paridade. talvez numa tentativa de diminuir a probahilidade de ronceher. O tempo médio de lactação para as mulheres que não usaram MAC é de 31.7 semanas para a paridade 1 e aumenta para 37.9 semanas no $5 .^{\circ}$ nascimento.

Segundo Chopra ${ }^{3}$ "numerosas classes de pílulas contraceptivas exercem algum efeito adverso sobre a lactação. Assim, reduzem a quantidade de leite e duração da lactação propriamente dita. Estes efeitos adversos são maiores se o emprego do contraceptivo começa nas primeiras semanas depois do parto e antes da plena lactação". "As pilulas contraceptivas preparadas principalmente a base de estrógenos exercem o maior efeito inibidor sobre a lactação. Em geral quanto maior é a dose de estrógeno mais pronunciado é o ifeito adverso solire a lactação".

Pela observação da regressão ajustada prarece-nos lícito aqui também inferir que à medida que a paridade aumenta há um aumento do tempo da lactação para as mulheres que não usaram MAC o mesmo não acontecendo para as que usaram.

\subsection{Tempo de Lactação e Tempo até a Gestução Seguinte}

Ohserva-se pela Tabela 6 que não existe relação entre o tempo de amamentação e temıo até a gestação seguinte para as mulheres que usam contraceptivos.

Analisando-se o comportamento das mulheres que não fazem uso de contraceptivos, ohserva-se que para todas as paridades à medida que o tempo de amamentação aumenta, aumenta também o tempo entre as gestações.
Ainda pela Tahela 7 analisamos na diagonal as percentagens das mulheres que engravidaram no fim da amamentação, acima da diagonal as mulheres que engravidaram algum tempo depois que deixaram de amamentar; e abaixo dela as que engravidaram enquanto amamentavam. Oliserva-se que para o $1 .^{\prime \prime}$ nascido vivo é maior a proporção das mulheres que engravidam algum tempo depois de terem interrompido a amamentação. A menor proporção se observa entre as que engravidaram enquanto amamentavam. Tal fato repete-se para todas as paridades estudadas. observando-se ainda que a diferença percentual entre as que engravidaram antes do desmame $e$ as que engravidaram depois ou concomitantemente é de mais de $80 \%$ para todas as paridades (Fig. 2).

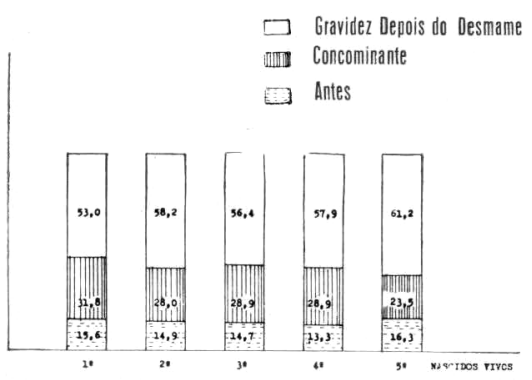

Fig 2 - Relação entre desmame e gravide 2 seguinte para mulheres que não usam contraceptivos, segundo ordem de nascimento.

\subsection{Tempo de Amamentação Segundo} Instruşão da Mulher na Entrevista

No presente trabalho a instrução foi tomada como indicador da situação sócioeconômica da mulher e sua família. tal como outras variáveis incluídas no estudo.

As informações de que dispomos não permitem avaliar o nível de instrução que a mulher tinha em cada momento de sua vida reprodutiva e. portanto, não podemos avaliar diretamente a influência da instrução sobre os hábitos da amamentação. 
YUNES, J. \& RONCHEZEL, V.S. - Estudo da lactaçåo em mulheres do Distrito de São Paulo, Brasil. Rev. Saude públ., S. Paulo, 9:191-213, 1975.

\section{TABEIA 6}

Distribuição percentual das mulheres que usaram métodos anticoncepcionais segundo tempo de amamentação e tempo até a gestaçăo seguinte (todos os nascidos vivos) do Distrito de São Paulo

\begin{tabular}{|c|c|c|c|c|c|c|c|c|c|c|}
\hline Tempo de lactação & $\begin{array}{c}<3 \\
\text { meses }\end{array}$ & $\begin{array}{c}3-5 \\
\text { meses }\end{array}$ & $\begin{array}{c}6-8 \\
\text { meses }\end{array}$ & $\begin{array}{c}9-12 \\
\text { meses }\end{array}$ & $\begin{array}{l}13-15 \\
\text { meses }\end{array}$ & $\begin{array}{l}16-18 \\
\text { meses }\end{array}$ & $\begin{array}{l}19-21 \\
\text { meses }\end{array}$ & $\begin{array}{l}22-24 \\
\text { meses }\end{array}$ & $\begin{array}{c}>2 \\
\text { anos }\end{array}$ & Total \\
\hline nāo amamentou & 0,6 & 0,6 & 0,7 & 1,5 & 0,6 & 0,7 & 0,4 & 0,6 & 4,0 & 9,7 \\
\hline$<3$ semanas & 0,6 & 0,5 & 1,5 & 1,0 & 0,7 & 0,3 & 0,7 & 0,7 & 2,2 & 8,2 \\
\hline 3-6 semanas & 0,5 & 0,6 & 0.7 & 0.7 & 0,6 & 0,4 & 0,6 & 0,6 & 3,2 & 7,9 \\
\hline 7-12 semanas & 0,6 & 0,4 & 1,0 & 1,4 & 0,6 & 1,2 & 1,0 & 0,4 & 3,4 & 10,0 \\
\hline 3-5 meses & 0,9 & 21,1 & 2,9 & 2.2 & 2,1 & 1,4 & 0,9 & 1,7 & 7,3 & 21,5 \\
\hline 6-8 meses & 0,4 & 0,6 & 1,7 & 1,4 & 1,3 & 0,9 & 1,1 & 0,5 & 4,4 & 12,3 \\
\hline 9-12 meses & 0,1 & 0,3 & 1,3 & 3,1 & 1.6 & 1,1 & 1,0 & 0,9 & 5,1 & 14,5 \\
\hline .13-24 meses & 0,4 & 0,4 & 0,3 & 1,0 & 1,1 & 1,5 & 1,7 & 1,0 & 6,6 & 14,0 \\
\hline$>2$ anos & - & 0,1 & 0,1 & 一 & - & - & 0,2 & 0,1 & 1,3 & 1,8 \\
\hline Total & 4,1 & 5,6 & 10,2 & 12,3 & 8,6 & 7,5 & 7,6 & 6,5 & 37,5 & 99,9 \\
\hline
\end{tabular}

TABELA 7

Distribuição percentual das mulheres que não usaram métodos anticoncepcionals segundo tempo de amamentação e tempo até a gestação seguinte (1.0 nascido vivo) - Distrito de São Paulo

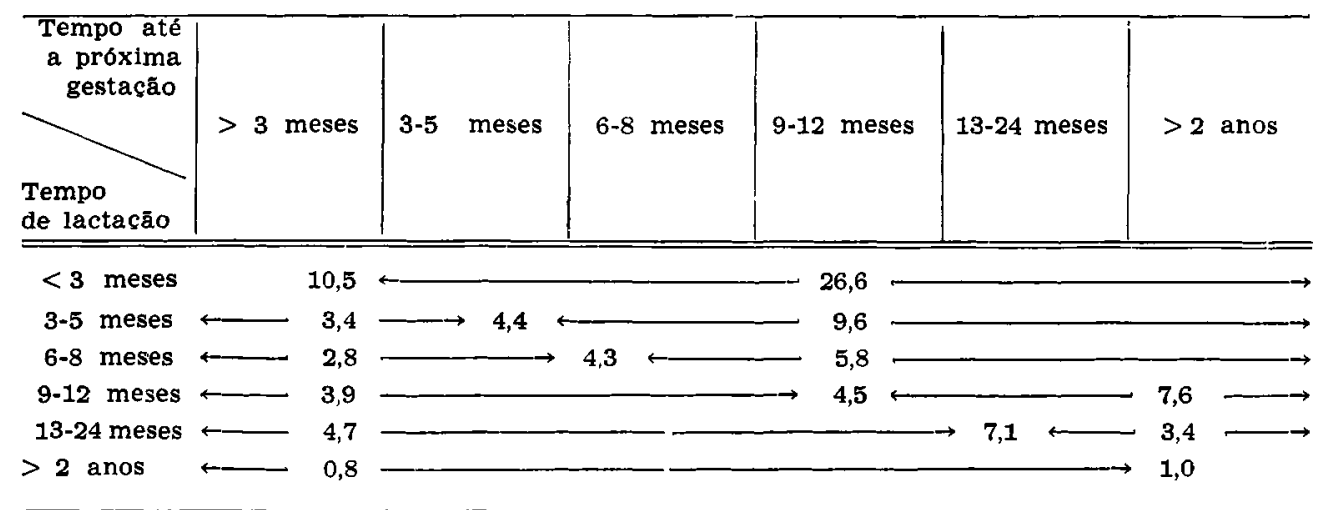

2 Diagonal - 31,8

$\Sigma$ Acima da Diagonal $=\mathbf{5 3 , 0}$

$\Sigma$ Abalxo da Diagonal $=15,6$ 
YUNES, J. \& RONCHEZEL, V.S. - Estudo da lactação em mulheres do Distrito de São Paulo, Brasil. Rev. Saúde públ., S. Paulo, 9:191-213, 1975.

A variável instrução da mulher foi dividida em 4 (quatro) categorias: analfabetas e mulheres que sabem ler e escrever sofrivelmente; primário (incompleto $\mathrm{e}$ completo), 1. ${ }^{\circ}$ ciclo (incompleto e completo) e $2 .^{\circ}$ ciclo (colegial) juntamente com o curso superior (incompleto e completo).

Pela Tabela 8 observa-se que, independente da paridade, há uma tendência das mulheres analfabetas e que sabem ler e escrever sofrivelmente, amamentar seus filhos por um periodo mais longo do que as mulheres com nível de instrução correspondente ao $20^{\circ}$ ciclo e ao curso superior. Assim é que $4,72 \%$ dos nascidos vivos de mães que pertencem à primeira categoria acima citada são amamentados por mais de dois anos, enquanto que apenas $0,50 \%$ dos nascidos vivos cujas mães estão ı.a última categoria são amamentados por esse mesmo período. Tal redução é gradual à medida que o nível de instrução cresce, sendo mais acentuada entre analfabetas e aquelas com instrução primária. Pela Fig. 3 nota-se que o mesmo fato ocorre ao se considerar a classe tempo de amamentação mais de um ano - para todas as paridades consideradas, com exceção da $4 .^{a}$ em que o $2 .^{\circ}$ ciclo e o curso superior apresentam uma percentagem de nascidos vivos amamentados no período um pouco maior que o secundário. Observa-se aqui também diferença maior entre a proporção de nascidos vivos de mães analfabetas e de mães com instrução primária que entre outros niveis se se considera duas classes vizinhas.

Observa-se a mesma tendência para todas as paridades em todas as classes de tempo observadas. Algumas flutuações verificadas para o $4 .^{\circ} \mathrm{e} 5 .^{\circ}$ nascidos vivos podem ser explicados pelo pequeno número de casos estudados. Para a classe de tempo de amamentação menos de 3 semanas observa-se que, independente da paridade, a maior proporção de nascidos vivos aí contida pertence a máes com grau

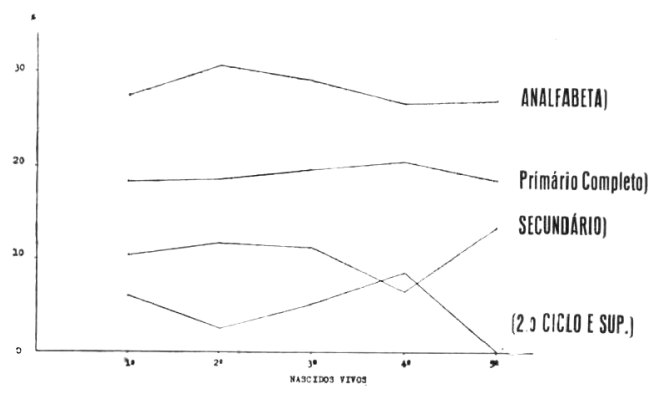

Fig. 3 - Distribuição percentual dos nascidos vivos amamentados, mais de um ano, segundo ordem de nascimento e grau de instrução da mulher.

de instrução correspondente do $2 .^{\circ}$ ciclo e o curso superior. Apenas $7,05 \%$ dos nascidos vivos de mães analfabetas e que sabem ler sofrivelmente são amamentados por um periodo inferior a 3 semanas, enquanto que $11,85 \%$ dos de mães com o grau de instrução mais elevado são amamentados pelo mesmo período. Considerando-se a paridade, observa-se essa mesma nítida diferença na proporção de nascidos vivos de mães analfabetas e de mães com nível de instrução mais elevada, para qualquer ordem de nascimento considerado, nessa classe de tempo de amamentação.

Poder-se-ia tentar explicar a relação inversa entre o tempo de amamentação e o grau de instrução admitindo-se a hipótese que as mulheres de menor grau de instrução pertencem à coorte mais velha, que por sua vez apresentam padróes culturais favoráveis ao hábito de amamentar. Tomas Szmerecsanyi ${ }^{11}$ refere que é fato sabido que as oportunidades educacionais ampliaram-se consideravelmente no Brasil e de modo especial no Estado de São Paulo nas duas ou três últimas décadas. Deste modo, é de se crer que as geraçōes mais jovens sejam mais escolarizadas que as mais velhas, podendo, por esta razão, estar menos ligadas a valores, normas e atitudes tradicionais. A diferença acentuada no hábito de amamentar entre mulheres analfabetas e mulheres com instrução primária pode tam- 
¡TNES, J. \& RONCHEZEL, V.S. - Estudo da lactação em mulheres do Distrito de São Paulo. Brasil. Rer. saúde públ., S. Paulo, 9:191-213, 1975.

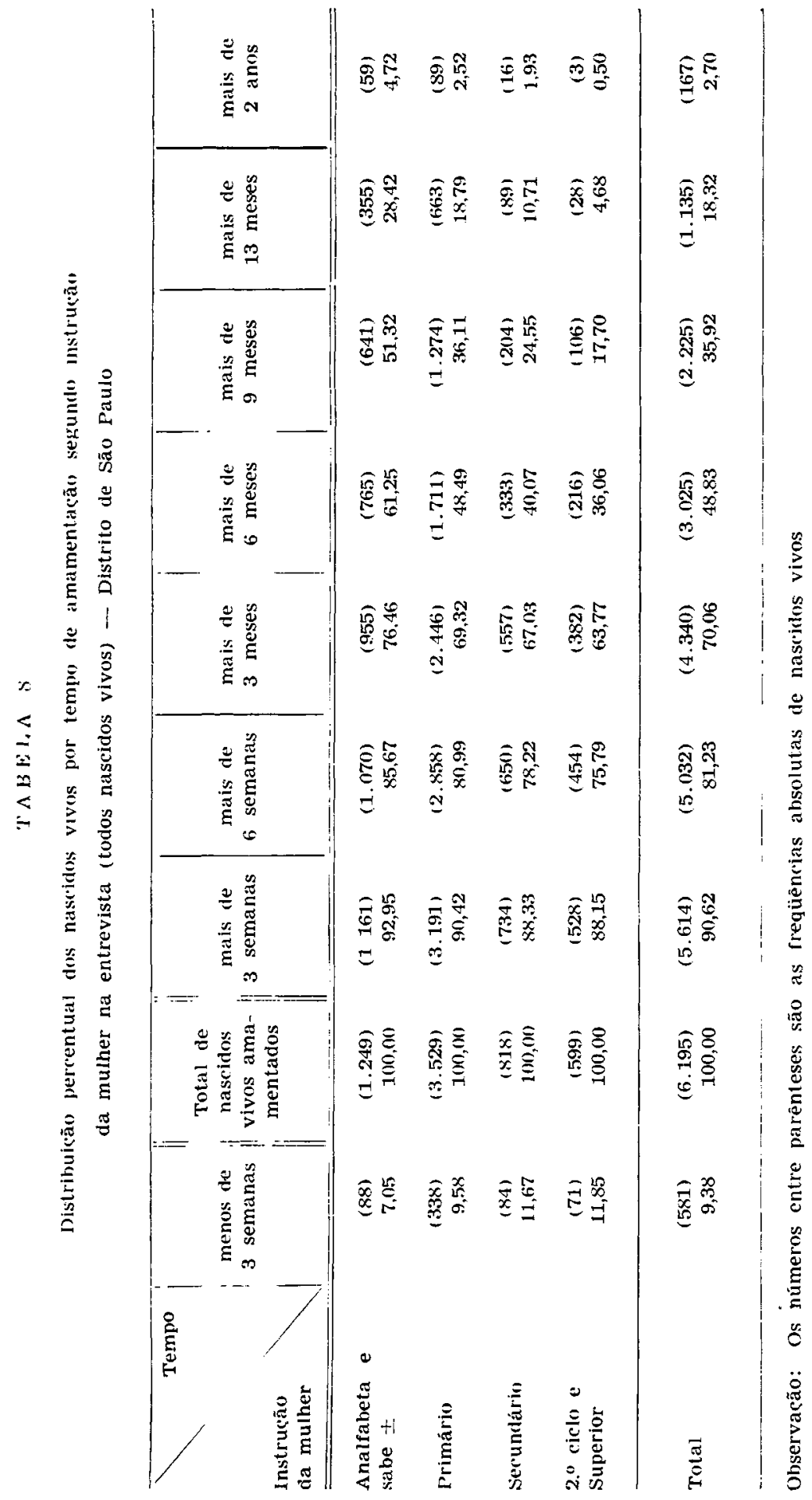


YUNES, J. \& RONCHEZEL, V.S. - Estudo da lactacão em mulheres do Distrito de São Paiulo Brasil. Rev, Saúde pübl., S. Paulo, 9:191-213, 1975.

lém ser devido à permanência das mulheres analfahetas nos trabalhos domésticos.

\subsection{Tempo Médio de Amamentaçâo (em semanas) por Paridade. Segundo Instrução da Mulher na Entrevista}

Considerando-se agora os tempos médios de amamentação segundo a instrução da mulher. conforme Tabela 9. algumas tendências podem ser observadas. Tomando-se as médias de tempo de amamentação para todas as ordens de nascidos vivos observa-se que as mulheres com nível de instrução inferior (analfabetas $\mathrm{e}$ sofrivelmente instruídas), amamentam $\mathrm{em}$ média seus filhos 39.8 semanas. As médias de tempo de amamentação decrescem à medida em que o nível de instrução se eleva. atingindo 21.7 semanas para as mulheres com curso colegial e/ou superior. Considerando-se cada paridade i] a 51 esta mesma tendência pode ser ohservada. Nota-se ainda que a diferença entre a duração do tempo de amamentação é maior entre os nascidos vivos de mães analfabetas e os nascidos vivos de mães com instrução primária 139.8 semanas e 31,5 semanas respectivamente - independente da paridade) do que entre os de mães com instrução primária (31.5 semanas) e os de instrução secundária (25.8 semanasi ou entre os de mães com instrução secundária e mães de instrução superior 121.7 semanas).

Considerando-se cada paridade. a mesma tendência pode ser observada sendo maior entretanto para o 3." nascido vivo em que as mães analfabetas amamentam em média 42.2 semanas e as com instrução primária amamentam em média 32.3 semanas havendo portanto uma diferença de 9.83 semanas (Tabela 9 ).

\subsection{Tempo de Amamentação Segundo Gasto Mensal da Família na Entrevistu}

Analisando-se a Tabela 10 ohserva-se que. independente da paridade. há uma tendência das mulheres cujas famílias gastam menos amamentarem por mais tempo que as das que gastam mais. A variável gasto mensal foi dividida nas seguintes classes: menos de $\mathrm{Cr} \$ 50.00$. de Cr $\$ 50,00$ a Cr $\$ 149,00$, de Cr $\$ 150.00$ a $\mathrm{Cr} \$ 249,00$ d d $\mathrm{Cr} \$ 250,00$ a $\operatorname{Cr} \$ 399.00$ - Cr $\$ 400,00$ e mais. Assim é que $7.89 \%$ dos nascidos vivos cujas mães gastam tna família) mensalmente menos de $\mathrm{Cr} \$ 50,00$ são amamentados mais de 2 anos enquanto que apenas $0.44 \%$ dos nascidos vivo: de mães que gastam mais de Cr $\$ 400.00$ são amamentados no referido período. A diferença observada entretanto só está relacionada às classes extremas de gasto: as intermediárias sufrem flutuaçōes não sendo possível identificar nenhuma tendência. Observa-se também que essa diferença decresce à medida que diminui o tempo de amamentação considerado 1 estão contidos na classe - tempo de amamentação mais de 13 meses $-21.05 \%$. dos nascidos vivos dos que pertencern a famílias rom gasto menos de Cr\$50.00 enquanto que apenas $7,00 \%$ dos que pertencem a familia com gasto mais de $\mathrm{Cr} \$$ $400.00)$.

Há ainda a considerar que as diferenças entre uma classe e outra de tempo de amamentação são maiores nos gastos maiores que nos menores, assim é que em famílias com gasto mensal inferior a $\mathrm{Cr} \$$ 50.00 . $55.20 \%$ dos nascidos vivos são amamentados mais de 6 meses. enquanto, $43.42 \%$ são amamentados mais de 9 meses tendo decrescido de uma classe para outra na proporção de $1.2: 1$. Para as classes de tempo mais de l:3 meses: $(21.05 \%)$ e mais de 2 anos $17,89 \%$ ) as proporções foram respectivamente 2.0:1.0 e 2,6:1.0, enquanto que nas famílias com gasto mensal superior a $\mathrm{Cr} \$ 400.00$ as proporçôes de decréscimos foram respertivamente $1.7: 1.0,3.2: 1.0$ e $15.9: 1.0$.

Considerando-se a paridade observa-se a mesma tendência isto é. as mulheres cujas famílias gastam menos amamentam mais temp" que as mulheres cujas 
YUNES, J. \& RONCHEZEL, V.S. - Estudo da lactação em mulheres do Distrito de São Paulo, Brasil. Rev. Saúde públ., S. Paulo, 9:191-213, 1975.

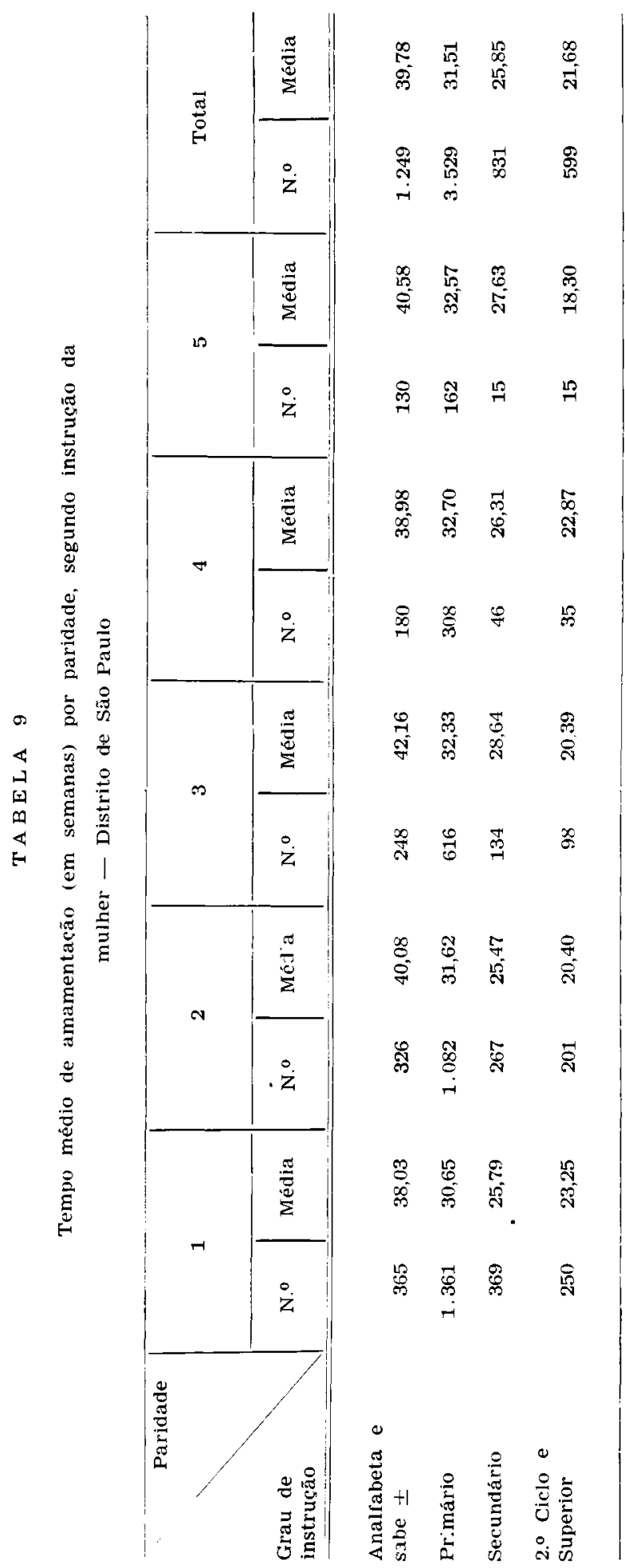


YLNES, J. \& RONCHEZEL, V.S - Estudo da la:tacão em mulheres do Distrito de São Paui Brasil. Rev. Saulle públ., S Paulo, 9:191-213, 1975.

famílias gastam mais. Essa diferença também só se observa nas classes extremas de gasto. Ohserva-se também que o 1." nascido vivo não segue nenhuma tendência. Para a classe - tempo de amamentação mais de $1: 3$ meses - observa$*$ que em todas as paridades consideradas a menor proporção encontrada são para os nascidos vivos de mães com gasto mensal de familia superior a Cr\$ 100,00 . Nas demajs classes de gasto não * ohserva nenhuma tendência.

\subsection{Tempo Médio de Amamentaçäo por Paridade Segundo Gasto Mensal da Familia na Entrevista}

Observando-ze as médias de tempo do amamentação ségundo o gasto mensal da família (Tabela 11). vê-se que existe uma diminuição do tempo de amamentação passando-se da categoria mais baixa de gasto mensal tgasto inferior a $\mathrm{Cr} \$$ 50.00 ) para a categoria mais alta aqui considerada (Cr\$400.00 e mais). Assim é que os nascidos vivos de mães cujas familias têm gasto inferior a Cr\$50.0n são. em média, amamentados durante 36.4 semanas. es nascidos vivos de mães (ujas famílias gastam mensalmente $\mathrm{Cr} \$$ 100,00 e mais são amamentados 23.9 sesmanas.

Levando-se em conta as diferentes paridades. a mesma tendência pode ser observada com exceção do primeiro nascido vivo. Essa tendência aparece mais nilidamente a partir do terceiro nascido vivo. comparando-se as classes extremas de gasto mensal de família.

\subsection{Tempo de Amamentaçāo Segundo a Origem da Mulher}

Analisando-se a Talela 12. verifica-se que independente da paridade os nascidos vivos com mãe de origem rural/urbana são amamentados por mais tempo que os nascidos vivos de mãe com origem urlana e da capital. Assim é que $4.44 \%$ dos primeiros são amamentados por mais de 2 anos enquanto que apenas $1.43 \%$ dos últimos ão amamentados por esse mesmo período. Observa-se que essa diminuição da percentagem é gradativa indo da área rural/urbana. rural. urbana e capital. Para as demais classes de tempo de amamentação observa-se major percentagem rural que rural/urbana ives Fig. 41.

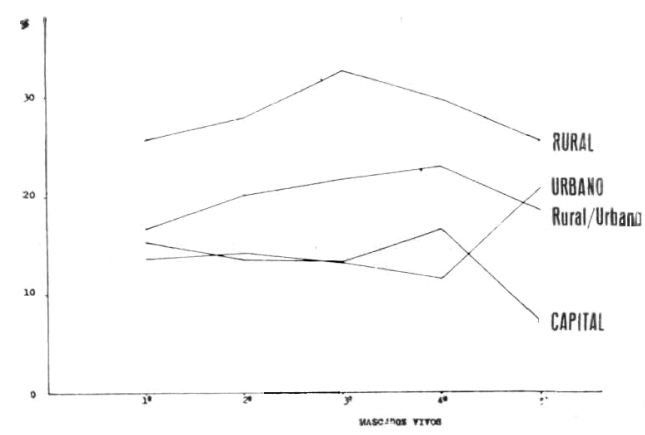

Fig. 4 - Distribuição percentual dos nascidos vivos amamentados, mais de um ano, segundo ordem de nascimento e origem $\mathrm{d}$ : mulher.

Observa-se ainda que a diferença entre o tempo de amamentação dos nascidos vivos de mulheres de zona rural/urhana e nascidas na capital vai diminuindo de acordo com a classe de tempo considerada. Temos para a classe mais de 2 anos a diferença de $4.44 \%$ (rural/ urbana) e $1.43 \%$ (capital), para mais de 13 meses temos $19.22 \%$ (rural) e $14.24 \%$ (capital); para mais de 9 meses temos $36.60 \%$ (rural/urbana) $29.98 \%$ (capital) e assim sucessivamente, deixando-nos concluir que a diferença entre mulheres de origem diferente no hábito de amamentar é maior à medida que o tempo de amamentação st. prolonga.

Ao se analisar os nascidos vivos amamentados menos de 3 semanas, observase que apenas $7.74 \%$ dos que pertencem às mães de origem rural estão contido. nessa classe, em relação a percentagem: mais alta nas demais origens. 
YLNES, J. \& RONCHEZEL, V.S. - Estudo da lactaçäo em mulheres do Distrito de São Pauic Brasil. Ret. Saude publ., s Paulo, 9:191-213, 1975.

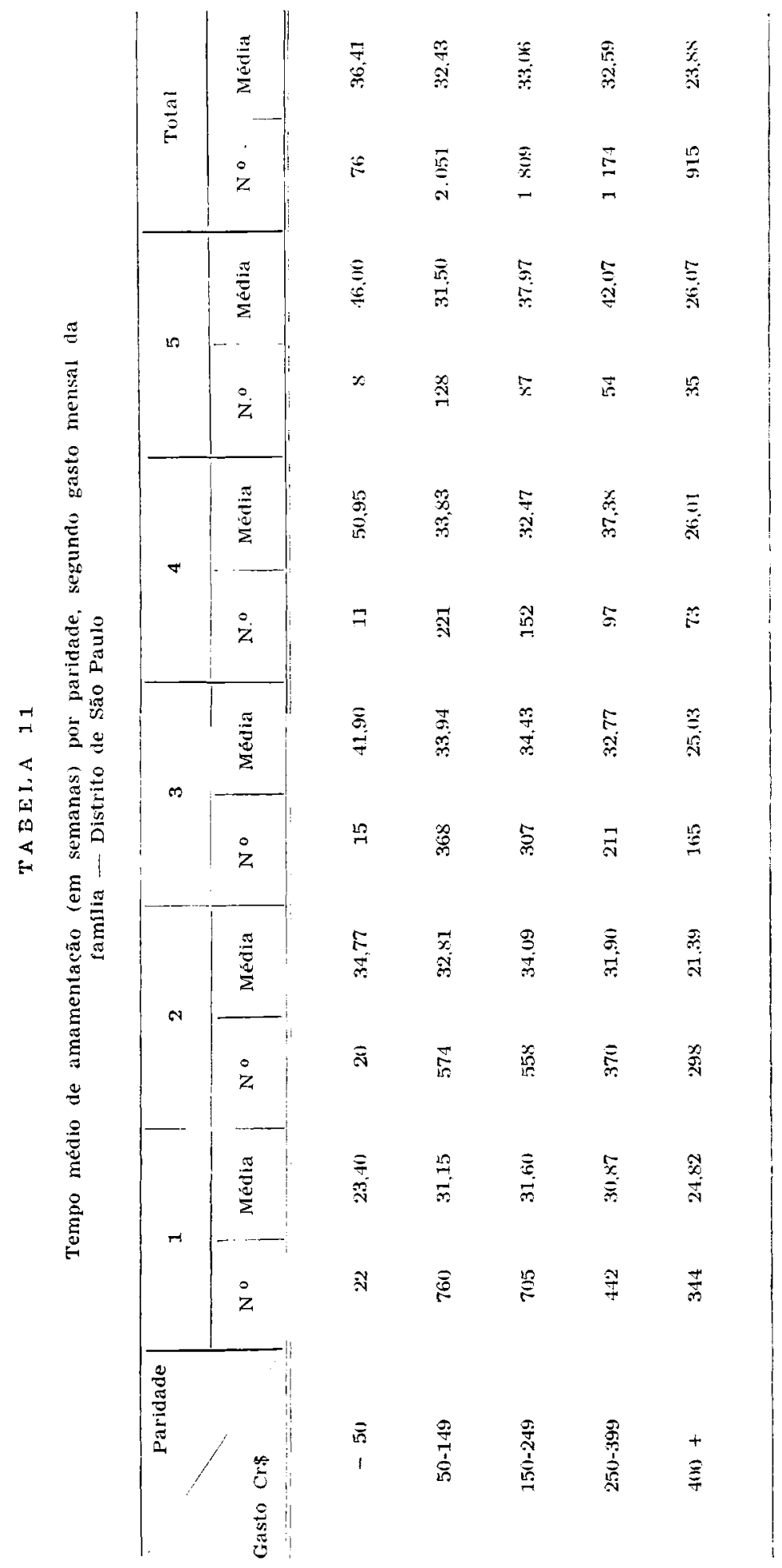


YUNES, J. \& RONCHEZEL, V.S. - Estudo da lactação em mulheres do Distrito de São Paulo, Brasil. Rev. Saude públ., S. Paulo, 9:191-213, 1975.

Contrariando a tendência não existe uma maior proporção dos nascidos vivos de mães nascidas na capital em relação às demais zonas de origem, contidas nessa classe de tempo (Tabela 12).

Ao se analisar por paridade observase a mesma tendência para os nascidos vivos $1 .^{\circ}, 2 .^{\circ}$ e $4 .^{\circ}$, ou seja, para os nascidos vivos amamentados mais de 2 anos é maior a proporção dos filhos das mulheres de origem rural/urbana, rural que de origem na capital. Para as demais classes de tempo observa-se maior proporção rural que rural/urbana para todas as paridades consideradas.

Para outros períodos considerados (mais de 13 meses - mais de 9 meses etc.) em geral há maior proporção das mulheres nascidas na Capital que das nascidas na zona urbana.

Para o $5 .^{\circ}$ nascido vivo há uma diferença na tendência devido, provavelmente. ao pequeno número de casos observados.

\subsection{Tempo Médio de Amamentação por Paridade Segundo a Origem da Mulher}

Observa-se que o tempo de amamentação independente da paridade varia, em média, de acordo com a origem da mulher. Assim, considerando-se o total de nascidos vivos para cada grupo de origem, o tempo médio de amamentação é maior para os nascidos vivos das mulheres de origem rural (38,6 semanas) que para as mulheres nascidas na Capital (28,12 semanas). Vale salientar a pouca diferença existente entre o tempo médio de amamentação para os nascidos vivos de mulheres nascidas na zona urbana e na Capital.

A mesma tendéncia pode ser observada considerando-se as diversas paridades com exceção do $4 .^{\circ}$ em que é maior o tempo de amamentação nas mulheres nas- cidas na Capital que na área urbana (Tabela 13).

O maior tempo de amamentação observado nas mulheres de origem rural pode ser explicado, em parte, devido a fatores culturais e predominância do estrato sócio-econômico baixo nesta classe.

\section{CONCLUSOES}

1 - A maioria das mulheres amamenta seus filhos, tendo variado esta proporção de $86,59 \%$ para a paridade 4 , a $88,99 \%$ para a paridade 2 e a duração média da amamentação variou de 30,2 semanas para a paridade 1 a 34,8 semanas para a paridade 5, aumentando também com a idade da mulher.

A moda do tempo de amamentação foi de 3 - 5 meses para as paridades 1 a 4 e de $9 \mid-12$ meses para a paridade 5 . Como explicação desta variação sugerese como hipótese a influência de fatores sócio-econômicos e culturais.

2 - Há uma tendência a aumentar com a paridade o hábito de não amamentar, a duração do tempo de amamentação para aquelas que amamentam e a proporção das que amamentam por mais de 9 meses.

3 - As mães que não usam contraceptivos amamentam durante um período mais prolongado do que as que usam e este tempo médio aumenta com a paridade.

A proporção de mulheres que amamentam seus filhos e usam contraceptivos concomitantemente é sempre maior do que aquelas que amamentam e não usam contraceptivos, exceto para a paridade 5 .

4 - Não existe relação entre o tempo de amamentação e tempo até a gestação seguinte para as mulheres que usam contraceptivos. Para as que não usam à medida que o tempo de amamentação aumenta, prolonga-se o intervalo entre as gestações. 


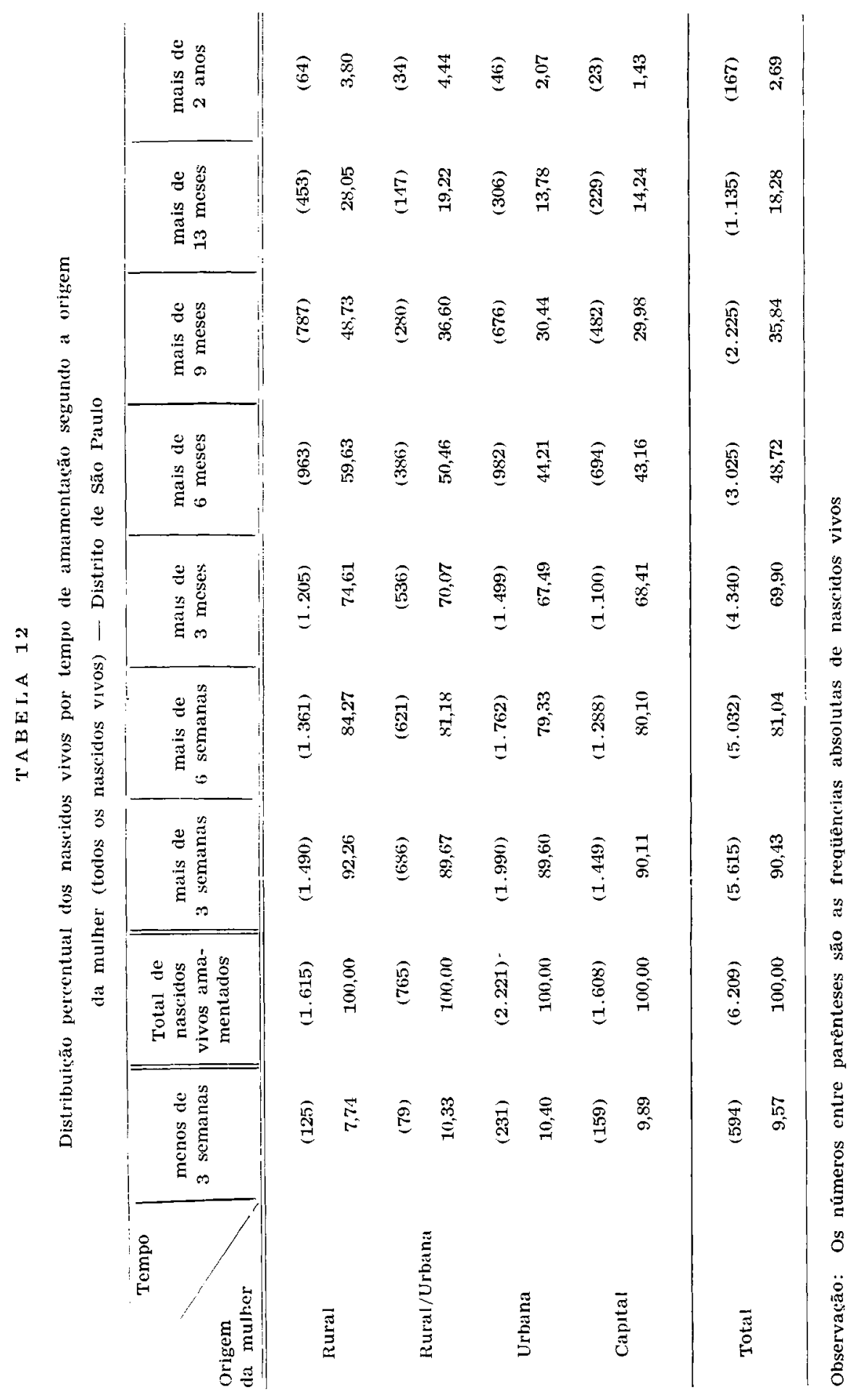


YLNES, J. \& RONCHEZEL, V.S. - Estudo da lactacão em mulheres do Distrito de São Paüto. Brasil. Rev. Saúde públ,, S. Paulo, 9:191-213. 1975.

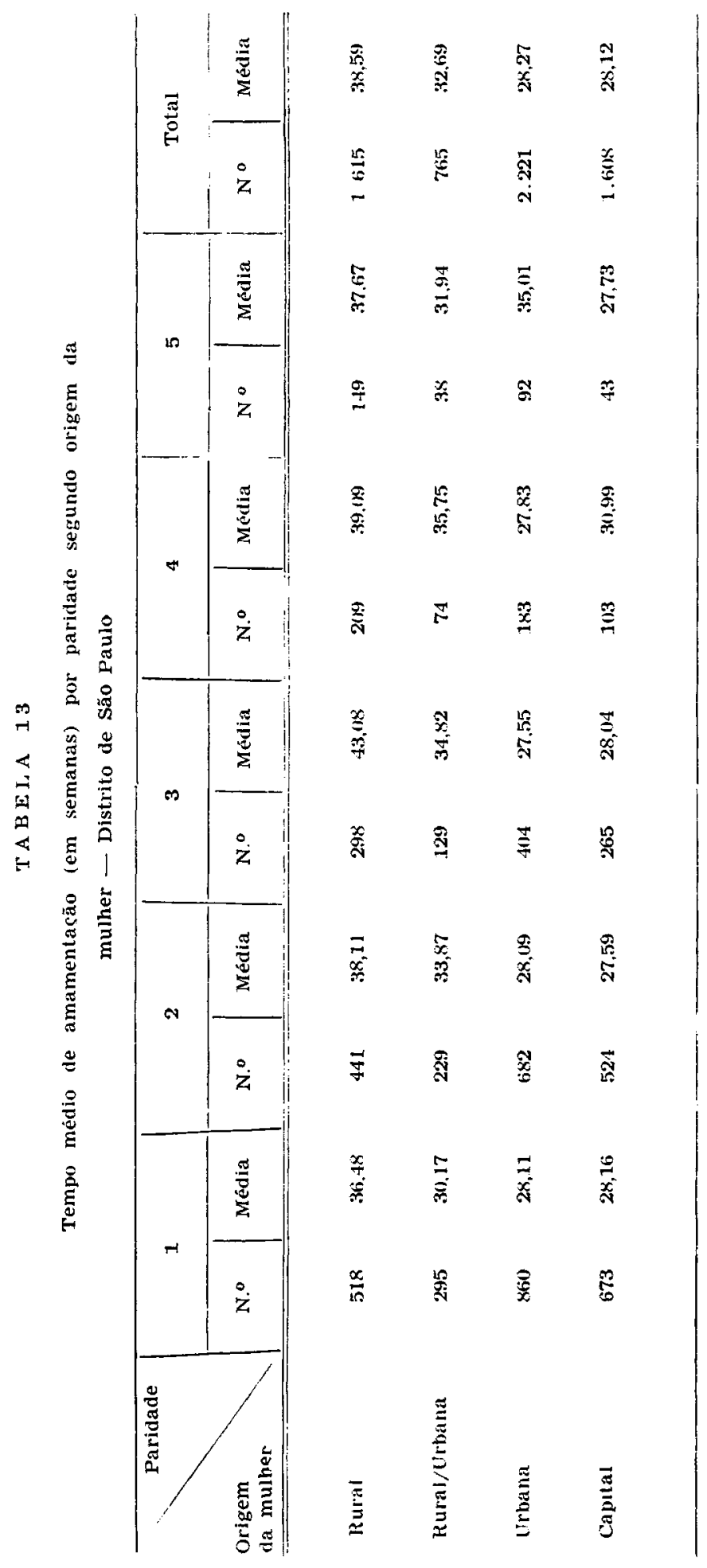


YNEs. J. \& RONCHEZEL, V.s. - Estudo da lactacāo em muiheres do Distuto de são Paulo, Brasil. Rev. Salude phbl. S. Paulo, 9:191-213, 1973

5 - Independente da paridade há uma tendêneia das mulheres com niveis de instrução mais elevadas amamentarem etus filhos por um período menor do que a: mulheres com niveis de instrução inferiores. () tempo médio de amamentacào decresce à medida que o nivel de instrução se elera sendo que a diminuição leste tempo é maior entre a classe de znalfahetas 139.8 semanas) to a lase com in-trução primária 13 L.5 semanas). Da mesma forma há uma tendência das mulheres culas familias tên um gasto mensal menor. amamentarem stus filho- por um período de tempo maior do que aque têm yasto mensal maior.

6 - O tempo de amanentação independente da paridade. varia em média de acordo com a origem da mulher. sendo maior nas de origem rural do que namulheres nascidas na Capital.

\section{RSPL-B 259}

ELNES, J. \& RoNCHEzel. V.S - LA study on the lactation of women in the District of S. Paulo. Brazll Rev. Saude públ., S. Paulo, 9:191-213, 1975

StMMARY: A study on the existing inter-relationshn betueen lartation and fertility and them socio-economic variables uas done on a sumple of the $S$. Paulo district women. Breast feeding lasted accoiding to the number of the months. age. level of educution and famly monthly expenses. A relationshu" between the feeding time and the mtervat between two subseruent megnames uas also found in women who don't use birth control methods.

Uniteras: Breast feeding. Lactation. Party.

REFERENCIAS BIBLIOGRAFICAS

BERQLó E.S et al - Lerels and variations in fertiluty in $S$ Paulo: Mhbank mem. Fr?. Quatt., 4613, pt. 21: $167-85.1968$

2 CAMARGO, C.P.F. \& BERQLO, E S.. ed Diferenciass de tertuidade CEBRAP. Caderno I $-s \mathrm{~d}$.

3. CHOPRA. J.G. - El efecto de los contraceptivos esteroldes sobre la lartacion. Bol. Otre sanit. panamer. 6: $491-509 . \quad 1973$.

GLTTMACHER, A F. - Fertily of man. Fertu. \& stern. 3:281-9. 1952.

5 JAIN. A K. et al. - Demormanher asperts of lactaton and anemorhea. John Hopkms Lniversit! - 1972 (unpublished)

r. LYON, R,A. \& STAMA, II J. - Onset of ovulation during puerperium. cahif. Hed, 65:99-103, 1946.

i. MC KEOWN, T. \& GIBSON, J P. - A note on menstruation and conception during lactation. J. Obstet Gundec. Brit. Eillp: 61:324-6. 1954.

- PECKHAl. C H. - An inrestigatum of some efects noted six months and one veal after delivers, $B u l l$, Johnis Hopk, Host , 34.156-207, 1934

9. POTTER, P G. et al. - Iactation and Its effects upor birth intervals in eleven Punjab villages. India $p_{i}$ bhe Health and Population chan. yes, Lnversity of Pittsburg, Press. 377-99:

11. ROBERTSON, W. - B - Bustfeedin practices: some implications of reglonal variations. Amer $J$, pht? Hith, $51: 1035,1961$.

11. SZMERECSANYI, T. - Mudanca veral e mudanca educacional - Boletm da Faculdade de Filosufia ciencias f Letras - Lniversidade de sāo Paulo. no 341), capitulo II, 1969

12. TIETZE, $G$. - The effect of breastfeeding on the rate of conception. In: International Population Conference. New York, 1965 Proceedngs $\because 2$. p $129-36$.

13. LDESKY, I.C. - ovulation in lactating Woman. Amer. J obstet gunee. 59:\$45-51. 1950 .

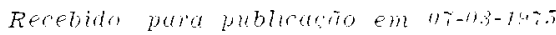

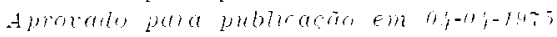

